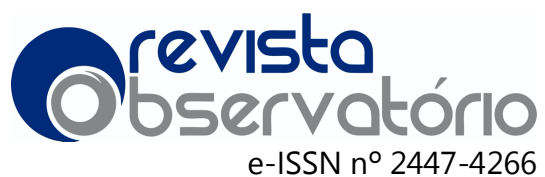

Vol. 6, n. 1, Janeiro-Março. 2020

\section{Ensino de sociologia da comunicação e percepções formativas}

Teaching of sociology of communication and formative perceptions

enseñanza de sociología de la comunicación y percepciones formativas

\section{Francisco Gilson Rebouças Porto Junior}

Doutor em Comunicação e Cultura Contemporânea (UFBA). Professor no Programa de Pós-Graduação em Comunicação e Sociedade (PPGCOM-UFT) e no Programa de Pós-Graduação em Propriedade Intelectual e Transferência de Tecnologia para a Inovação (PROFNIT-UFT). E-mail: gilsonporto@uft.edu.br.

(1) 0000-0002-5335-6428

\section{Joselinda Maria Rodrigues}

Mestre em Comunicação e Sociedade (UFT). E-mail: jomariarodrigues@hotmail.com

(1) 0000-0001-9192-2702

Correspondência: Universidade Federal do Tocantins. Quadra 109, Norte, Avenida NS 15, Plano Diretor Norte. 77001090 - Palmas, TO - Brasil.
Recebido em: 16.11.2019.

Aceito em: 19.12.2019.

Publicado em: 03.01.2020.

\begin{abstract}
RESUMO:
Vivenciamos uma avalanche de notícias falsas sobre a realidade dos fatos. Notícias verdadeiras podem ser a diferença entre viver ou morrer para milhões de pessoas em todo o globo embora o acesso a notícias verdadeiras possa ser privilégio de poucos. Este texto apresentará aspectos da sociologia da comunicação, sua relevância na formação jornalística e resiliência do jornalista - o porquê do ensino de sociologia no curso de jornalismo. Observase que a displicência é glocalizada. Observam-se condutas displicentes em países desenvolvidos e periféricos, nos dois hemisférios, portanto há deficiência da e de sociologia da comunicação. Os grandes contingentes displicentes continuam precisando de analistas que lhes apresentem notícias sem filtros intencionais, papel que cabe ao jornalismo sério que atua incansavelmente na busca de informações verdadeiras mesmo sob o achincalhe de políticos e empresários, atuando como "guardião da sociedade."

PALAVRAS-CHAVES: Sociologia do Jornalismo; Formação; Comunicação; Notícias falsas.
\end{abstract}

\section{Introdução}

Atônitas pessoas ao redor do mundo escrutinam noticiários em busca de informações confiáveis sobre a terrível pandemia do Covid19 em uma avalanche de notícias falsas sobre a realidade dos fatos. Notícias verdadeiras podem ser a diferença entre viver ou morrer para milhões de pessoas em todo o globo embora o acesso a notícias verdadeiras possa ser privilégio de poucos. Notícias variam sobre a letalidade da doença, medidas de prevenção e medicamentos que podem surtir efeito no tratamento da afecção, porém também neste aspecto são os cidadãos periféricos de países periféricos os mais prejudicados em se tratando de informações confiáveis. 


\section{Orevisto}

Vol. 6, n. 1, Janeiro-Março. 2020

O prejuízo destas populações em países densamente povoados como o Brasil cuja população é superior a 211 milhões de pessoas pode ser verificado na ignorante displicência das classes C e D no tocante ao isolamento social. Notícias recorrentes da inconsciência destas populações e consequente exposição por vezes desnecessária ao contágio têm sido associadas a atitude de algumas lideranças políticas e religiosas. Nos cinco continentes observaram-se líderes de países com discursos "inconsequentes" e omissão de informações (BBC, 2020; IBGE, 2020; DATAFOLHA, 2020).

"Uma gripezinha ou resfriadinho" já é responsável por mais de cem mil mortes e dois milhões de pessoas infectadas em todo o globo, números que são tragicamente atualizados a cada minuto tal a gravidade da pandemia ${ }^{1}$. Parte deste cenário resulta dos ruídos da desinformação descrita por Wardle (2017) como: "[...] information that is false and deliberately created to harm a person, social group, organization or country." (p. 20)

Indicações associam a desinformação deliberada neste cenário pandêmico a interesses econômicos. Possivelmente países que enfrentam altos índices de contaminações e vítimas retardaram temerariamente suas ações "temendo" as atuais previsões do Fundo Monetário Internacional - FMI, de que a economia mundial enfrentará recessão nos moldes de 1929. (PÚBLICO, 2020).

A imprensa mundial que tem trabalhado exaustivamente para neutralizar e com sorte desfazer os efeitos da desinformação, apesar de ataques que lhe são desferidos por governos e empresas resiste estoicamente, resistência que pode estar fundamentada na missão do jornalista apresentada por Melo (2000, p. 16):

O compromisso essencial do jornalista está na esfera do bem comum, das aspirações coletivas. Trata-se de um ser apartidário, desapaixonado, neutro, probo e elegante, capaz de perceber todos os fatos, ainda que eles possam parecer vulgares, interpretando-os pela ótica do interesse público.

1 "Em 11 de março de 2020, a Organização Mundial da Saúde declarou o surto uma pandemia.[9][10] Até 15 de abril de 2020, pelo menos 2006 513[3] casos da doença foram confirmados em mais de 210 países e territórios, com grandes surtos nos Estados Unidos (mais de 611000 casos), Espanha (mais de 174000 casos), na Itália (mais de 162000 casos), Alemanha (mais de 132000 casos), França (mais de 103000 casos), Irã (mais de 75000 casos) e China continental (mais de 82000 casos).[11] Pelo menos 128886 pessoas morreram (mais de 25000 nos Estados Unidos, pelo menos 21000 na Itália, cerca de 18000 na Espanha, por volta de 15700 na França, mais de 12000 no Reino Unido e pelo menos 300 na China) e 501758 foram curadas." Disponível em <https://pt.wikipedia.org/wiki/Pandemia_de_COVID-19>. Acesso 15 abril de 2020. 


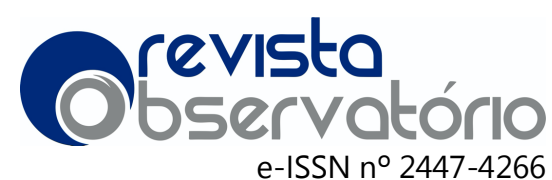

Vol. 6, n. 1, Janeiro-Março. 2020

Este texto apresentará aspectos da sociologia da comunicação, sua relevância na formação jornalística e resiliência do jornalista - o porquê do ensino de sociologia no curso de jornalismo.

\section{Sociologia da comunicação - para quê?}

Entender o efeito da comunicação entre o emissor e o receptor é um dos percursos que a sociologia da comunicação pode fazer uma vez que as comunicações jornalísticas produzem reações e consequentes tomadas de decisão, exemplificadas pela imposição de quarentena para cidadãos infectados pelo Corona vírus e o lockdown que esvaziou cidades em cinco continentes, como se os media "misticamente" controlassem o desenrolar dos acontecimentos. (RODRIGUES, 2018, p. 35).

Implicações místicas à parte, a sociologia da comunicação tem investigado a teoria da agenda-setting, a teoria da tematização, os estudos do newsmaking, a teoria do diferencial cognitivo e a teoria crítica dos media e dos seus efeitos a fim de entender o comportamento do jornalismo diante de um público que pode escolher o formato da informação que vai consumir. Encontram-se mais de trinta formas de oferecer conteúdos digitais, além dos formatos tradicionais como jornal, rádio e televisão.

A agenda-setting dos últimos cinco meses está voltada para a pandemia, cumprindo sua função: "Os media definem uma orientação cognitiva essencial dos indivíduos (no que respeita à forma de condução de sua atenção relativamente a determinados temas ou assunto)", todavia, margeando outras agendas de interesse nacional como a dengue, zika e Chikungunya, das crianças microcéfalas recusadas por escolas, de Brumadinho, e do desmatamento recorde da Amazônia. (RODRIGUES, 2018, p. 37).

Estar a agenda-setting voltada para a pandemia relaciona-se com a teoria da tematização que conforme Rodrigues (2018) é, "uma hierarquização dos assuntos a nível da agenda pública em conformidade com a importância atribuída a esses mesmos pela agenda dos media." (p. 36). Esta teoria confirma a força do jornalismo no que Thompson (2011) identifica como "quarto poder", o qual tem sido usado na maioria das vezes em defesa dos interesses da sociedade, infelizmente em alguns países, à custa das vidas de jornalistas.

A sociologia da comunicação busca entender os veículos de comunicação nas investigações e divulgações que fazem, em que momento e por que razão decidem a hierarquia do lead (quem, o que, onde, por que, quando e como) e em se tratando da pandemia como foi ressaltado acima, percebem-se veículos alinhados ou não com as 


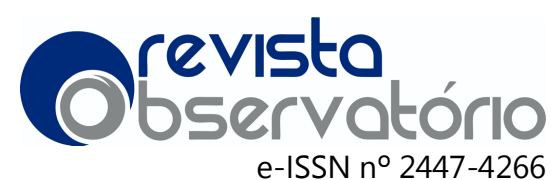

Vol. 6, n. 1, Janeiro-Março. 2020

políticas de saúde adotadas em alguns países. A conceituada revista inglesa The Lancet critica a conduta do Presidente Jair Bolsonaro diante da pandemia e a lentidão do Reino Unido, dos Estados Unidos e Suécia diante da gravidade da pandemia: " Brazil's President Jair Bolsonaro has been strongly criticised by health experts and faces an intensifying public backlash for what is seen as his weak response." Neste artigo específico observase que o lead destaca o que, apesar de os atores envolvidos serem figuras de destaque internacional, como o presidente americano Donald Trump e o primeiro ministro britânico Boris Johnson: "Covid19: learning from experience." (THE LANCET, 2020). (Negrito nosso).

Assim, entende-se que o fato a ser noticiado decidirá que pergunta será respondida pela notícia (comunicação). Voltando à pergunta: sociologia da comunicação - para quê, pode-se dizer que é para entender como a notícia (comunicação) é construída e como os media atuam durante sua construção. A sociologia da comunicação analisa a mensagem, investiga o que a mensagem quer comunicar. (RODRIGUES, 2018). Ato contínuo, isto a torna disciplina importante no ensino de jornalismo, conforme a discussão que segue.

\section{Em defesa do ensino de sociologia nos cursos de jornalismo}

A introdução deste texto descreve minimamente a realidade de acontecimentos relacionados ao Covid19, porém evoca a aglutinação que Marques de Melo (2011) fez da sociedade pós internet - sociedade glocalizada, global e local, onde acontecimentos locais podem ganhar proporções globais como a pandemia que aflige a população mundial.

O jornalista do século XXI investiga para informar uma sociedade glocalizada e neste contexto o ensino de sociologia pode ampliar sua visão de mundo auxiliando-o a interpretar os diversos eventos que se apresentem sob uma perspectiva científica adequada àquele fato. Sob que aspecto ou aspectos um fato pode ser analisado?

Tomem-se como exemplo as diversas reportagens sobre o Corona vírus. Diz-se que o marco zero da pandemia Covid19 foi a cidade Wuhan onde, nas feiras livres o abate e comércio de animais domésticos e silvestres era permitido, favorecendo a contaminação viral (WESTCOTT, 2020). Fatos desta natureza podem ser analisados à luz da sociologia cultural e antropologia.

A academia pode prover subsídios teóricos ao estudante de jornalismo de modo que ele compreenda: "[...] em que medida a cultura exprime estruturas mentais inatas do homem, em que medida ela é adquirida e quais são os processos neuropsíquicos dessa aquisição" (LÉVI-STRAUSS 2012, p.136). Esta compreensão propiciará ao futuro jornalista 


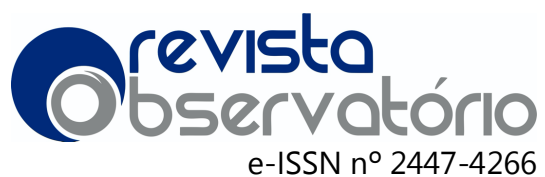

Vol. 6, n. 1, Janeiro-Março. 2020

analisar um fato sob diferentes facetas. Em uma notícia sobre Wuhan, o lead (o que, por que - razões culturais) poderia evitar julgamentos equivocados e xenofóbicos como têm sido observados nas redes sociais.

\section{O que dizem professores do Brasil e Portugal?}

Docentes pesquisados em cursos de comunicação e jornalismo em universidades brasileiras e portuguesas revelaram segundo a pesquisa que: "por entenderem a responsabilidade da mídia enquanto alimentadora das massas, são sensíveis à necessidade de os estudantes inteirarem-se das questões pertinentes à sociedade, e da importância do equilíbrio entre teoria e prática." (RODRIGUES, 2018, p. 96) Isto significa que sob a ótica dos professores entrevistados, apesar do enxugamento dos currículos, ainda assim é imprescindível que o estudante de jornalismo tenha suficiente base teórica, para dialogar com a sociedade e sobre a sociedade.

O trabalho de entrevistas para a pesquisa começou na Universidade Federal da Bahia - UFBA, universidade que não inclui a sociologia na matriz curricular, como acontece com a Universidade Federal do Tocantins - UFT e as universidades portuguesas. A Universidade Federal da Bahia - UFBA, foi escolhida como contraponto à Universidade Federal do Tocantins - UFT e as Universidades Portuguesas da Beira Interior, Católica Portuguesa, de Lisboa, do Minho e Nova de Lisboa, e por isso o preâmbulo das entrevistas realizadas $^{2}$ foi diferente do usado nas demais; porém, ato contínuo, as entrevistas seguiram um roteiro único. A princípio, as perguntas foram centradas sobre as possíveis críticas ao conteúdo teórico, para conhecer as experiências dos docentes com o ensino de sociologia, seguidas da percepção docente acerca da relação entre um bom embasamento teórico e o impacto desse tipo de formação, com o objetivo de verificar se as críticas apontadas por Teixeira $\left(2012^{3}\right)$, condiziam com a realidade da sala de aula.

A primeira entrevistada, professora de técnica S I, Dra. Salvador I da UFBA, reconhece que grosso modo para os alunos, os conteúdos teóricos são dispensáveis: “Eu

\footnotetext{
2 O ensino de sociologia da comunicação, se iniciado pela sociologia geral, auxiliaria os discentes quando profissionais a elaborarem melhores interpretações da realidade (para o jornalista) e realizar estudos e pesquisas mais aprofundados (para o produtor cultural) na área de comunicação e cultura?

${ }^{3}$ Um outro aspecto que ressalta de uma análise individual de cada um dos planos de estudo é a presença de uma elevada carga horária de disciplinas teóricas do campo das Ciências Sociais e Humanas. Que razão poderá estar por trás deste aspecto? Apenas permitir, aos alunos, um maior conhecimento do mundo? Uma necessidade de manter a tradição? Possibilitar o aproveitamento dos recursos humanos existentes, nomeadamente professores, que já são "da casa", mesmo que de outras áreas (ciências sociais, humanidades, línguas, literaturas, áreas sem alunos), mas que convém manter (TEIXEIRA, 2012, p. 418).
} 


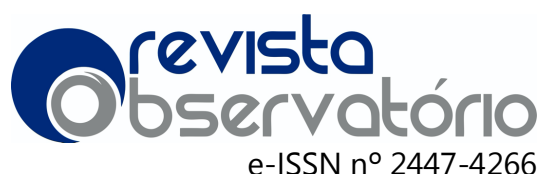

Vol. 6, n. 1, Janeiro-Março. 2020

acho que lamentavelmente eles ainda chegam achando que teoria é uma abstração dos deuses ou a Bíblia, do Olimpo, quase que uma abstração que não, parece não fazer sentido e que eles gostariam mesmo de desenvolver alguma coisa prática.[...] Então quando eles estão na sala de aula e dizem que não querem fazer uma monografia porque eles acham que monografia exige mais leituras, mais reflexão e pensam em fazer um produto. Eu digo que não tenho nada contra; que os preparo para as duas terminalidades, mas que devem pensar o seguinte: o produto é um trabalho bruto. Você vai realizar o produto, mas depois no memorial você vai falar, vai refletir sobre a sua realização, então você não tem de maneira nenhuma como escapar dessa suposta, equivocada polarização que você traz".

Questionar polarizações entre teoria e técnica é uma prática saudável no ensino. Espera-se que a universidade como espaço de produção de conhecimento, proveja preparo profissional, não apenas técnico e utilitarista, mas do tipo polimorfo, ao qual é indispensável o arcabouço teórico (LARANJEIRA, QUADROS E CAETANO, 2011), como defendido pela professora de técnica P II, Dra. Palmas II, da UFT: "eu dou a disciplina de técnica P II. Se a gente for pensar, seria uma disciplina técnica de P II, mas eu trabalho com uma carga teórica bem grande na disciplina porque eu acho que não é só produzir $x$, mas a gente tem que resgatar essa ideia de, do papel social da sociologia, do papel antropológico, político, ao longo do tempo. Como surgiu $x$, é a história de $x$, não tem como não linkarisso na disciplina de P II. Então, eu busco trazer essa carga teórica sim na minha disciplina de P II."

O exercício de sensibilização do olhar realizado pela professora Dra. Palmas II, concorda com Dib, Aguiar e Barreto apud Teixeira (2011), que advogam a prática docente como atividade de reflexão, observação e questionamento; em função da complexidade dos processos sociais, que P II não dá conta sem contextualizações. É muito feliz o esforço de interdisciplinar as matérias oferecidas na graduação em comunicação, tanto no Brasil como em Portugal, especialmente em virtude,

[...] dos impactos das tecnologias de informação e comunicação, produzindo e mantendo conhecimentos científicos e técnicos, bem como em transformar tudo em inovações econômicas e sociais, é mais importante do que nunca para o dinamismo, soberania e prosperidade das sociedades. ${ }^{4}$ (JAMBEIRO e PALÁCIOS, 2010, p. 7). (Tradução da autora).

\footnotetext{
4 "[...] the impacts of information and communication technologies, producing and maintaining scientific and technical knowledge, as well as transforming it into economic and social innovations, are more important than ever for the dynamism, sovereignty and prosperity of societies."
} 


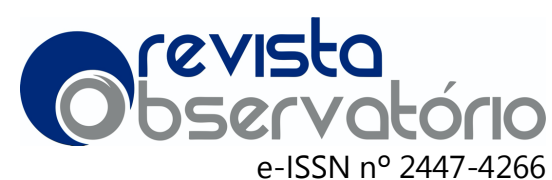

Vol. 6, n. 1, Janeiro-Março. 2020

Críticas como a presença de matérias teóricas no curso de comunicação, talvez sejam reflexo da formatação que a mídia imprimiu às comunicações. O comunicólogo formado na academia, inserido no mercado de trabalho, pode constatar que desperdiça suas potencialidades ao produzir informação sem conteúdo comunicacional, conforme o modelo vigente de notícias rápidas, porém, precisa fazê-lo, uma vez que os veículos dependem da audiência, se quiserem a fidelidade dos anunciantes, e o jornalista, do emprego. O professor de teórica L III, Dr. Lisboa III, da Universidade Nova de Lisboa, docente da cadeira teórica L III há mais de 30 anos, constata : " [...] é um problema que tem muito mais a ver com as condições institucionais ou de funcionamento da mídia do que propriamente com as condições da formação acadêmica necessárias, embora eu ache também que por causa disso há uma contaminação desse modelo para a própria formação e vamos para aquilo que eu falava há pouco, não é, de como até no meio acadêmico já se vai generalizando um discurso, de que o que se precisa é prática, prática, prática. Entramos numa emulação com os próprios meios de comunicação, já não há uma diferença entre o que é trabalhar profissionalmente e o que é fazer uma formação acadêmica e científica."

Nota-se que para os professores é totalmente exequível a presença da teoria e técnica no curso de comunicação, contudo, como o Prof. Lisboa III apresentou, a academia não pode se afastar de sua missão científica. A professora de teórica B I, Dra. Beira Interior, da UBI, entende que: "Uma pessoa que trabalha com comunicação tem que saber compreender o mundo, tentar compreender o mundo [...]", compreensão exercitada pelas ciências humanas, como x: "e eu tenho sempre a ilusão de que x serve um pouco para a compreensão do social." $\mathrm{Na} U \mathrm{BI}$, a docente nunca foi questionada quanto ao ensino de $x$, o que para ela parece negativo, por entender que questionamentos são saudáveis: "Não, não, até agora não porque podiam fazê-lo perfeitamente, mais não, não...[...] isso é um queixamento dos professores, nós gostávamos de ter alunos mais ativos, mais críticos, mais..., gostávamos, aqui e em todo lado, acho eu, mas não temos esses alunos não, eles não são assim tão, tão...".

Compreender o mundo para trabalhar com comunicação pode requerer esforços estrênuos para os que forem formados apenas em bases tecnicistas crendo que a técnica dá conta de questões subjetivas. Obviamente, as TICS obrigaram mudanças no formato das comunicações e é louvável que as instituições tenham se adequado ou estejam se adequando a elas, entretanto, convém aos espaços formativos estarem alertas ao que parece uma benesse da convergência, mas que pode ser uma forma de intromissão 


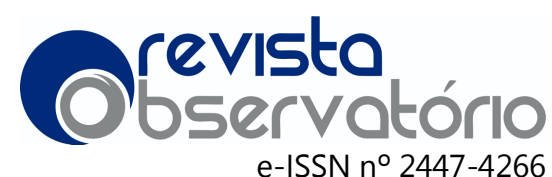

Vol. 6, n. 1, Janeiro-Março. 2020

demasiada do mercado no espaço acadêmico, portanto, o equilíbrio pode ser um inestimável argumento contra a concentração de disciplinas. Conforme a professora de técnica S II, Dra. Salvador II, da FACOM/UFBA: "[...] o desenho dos cursos não é muito bom em geral, [...] porque se os cursos têm uma dimensão mais técnica que não conversa com a perspectiva teórica que está posta, é problema do desenho do curso, [...], você deve preparar para tecnicamente esses profissionais terem condições de desenvolver bem os seus ofícios, né? O problema é que na hora que você oferta um conhecimento mais abstrato ou mais teórico, ele não é pensado, no processo da formação, para que quem tá lidando com ele entenda o que é que ele pode significar ou não, [...] uma formação que não vai ver uma relação direta com a prática - não precisa ver, mas se ele entender porque ele vai saber aquilo, ou porque que aqueles autores existem, ou a relação daqueles autores com o que ele vai precisar hoje de algum modo, o que foi mudando ou não ao longo do processo, acho que é um desenho de curso, que foi se perdendo a forma de relacionar as duas coisas."

Esse relacionar as duas coisas ou interdisciplinaridade é o objetivo de dez em dez instituições de ensino, mas de difícil consecução, ainda assim, ela se mostra como a forma mais próxima de os alunos aprenderem como usar a teoria para desenvolver a técnica. Fidalgo (2001), antenado com as tecnologias digitais entende que mesmo diante das novas tecnologias de comunicação, os alunos ainda precisam de embasamento teórico. O contato diário com as tecnologias digitais "ensina" aos alunos duas verdades importantes: $1^{\text {a }}$. As novas TICS exigem a mesma preparação teórica que os antigos meios de comunicação exigiam e $2^{a}$., ainda exigem o componente intelectual e criativo, que para o autor, é mais difícil que o componente técnico.

O aluno calouro desenvolve a capacidade crítica gradualmente, e a grande maioria quando questiona a matriz curricular, o faz nos semestres finais do curso, mas, parece apropriado que o aluno seja lembrado que "só se aprende a técnica, conhecendo a teoria", segundo o professor de teórica P I ${ }^{5}$, Dr. Palmas I, da UFT. Refletindo bem, a crítica de Teixeira (2012), é feita em um trabalho de pós-graduação, confirmando a observação que o Prof. Palmas I faz: "[...] talvez o curso produza isso, [...] quando eu dava a disciplina final que era política brasileira, final do curso já, é lá no final do curso, que aí vem aquela dicotomia falsa, é, vamos falar coisa mais prática? Vamos ser práticos e tal [...] então foi o curso que produziu e o curso pode produzir isso mesmo, aí é uma coisa que você pode

\footnotetext{
${ }^{5}$ Informação disponível em < http://docs.uft.edu.br/share/s/jBzULuM8S5meaOLhLEr3XA > .Acesso em 25 jan. 2018.
} 


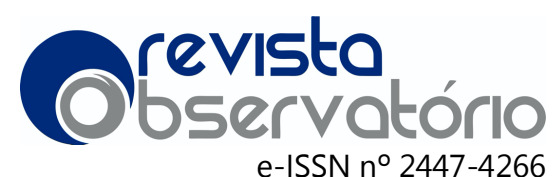

Vol. 6, n. 1, Janeiro-Março. 2020

explorar bem talvez porque faz parte um pouco da, ao meu ver isso aí faz parte um pouco da posição do jornalismo na sociedade e no mundo da, vamos dizer do conhecimento da ciência [...]". Existe então a suspeita de que o discurso tecnicista é culturalmente produzido, como Lisboa III aventou em parágrafo anterior.

A percepção e conduta das/dos docentes é semelhante mesmo estando espacialmente dispersos. Diante de questionamentos como os apresentados acima críticas ao conteúdo teórico, a professora de técnica III, Dra. Palmas III, da UFT, reage do seguinte modo: "[...] mesmo eu ministrando uma disciplina prática, eu tento dizer para eles em cada conteúdo eu mostro que, que aquilo ali pode ser melhor. Você pode ter uma atuação melhor em determinado procedimento, em determinado método do jornalismo se você tiver essa orientação humanística, esse olhar sociológico, esse compreender as comunidades, os grupos sociais, [...], que não é só técnica. Na minha disciplina eu falo pra eles: olha, a técnica, [...] um mês de redação, a redação ensina muita coisa, mas, esse olhar comprometido com a sociedade, esse olhar ético, esse olhar construtivo, esse olhar que vê uma comunidade periférica, um grupo social de outro forma, diferente - esse olhar, é só com estudo, com as disciplinas de humanas, das ciências sociais, as disciplinas que trabalham mais o conteúdo da sociologia, e da antropologia, da história, ciência política, filosofia."

As técnicas de redação, o uso das tecnologias e a linguagem digital são pelo menos no mundo ocidental, universais, apresentando talvez mínimas variações. Os meios de comunicação têm mínima variação de objetivos, mas o sentido da comunicação, esse sim tece a teia de significados, que é a cultura. Os significados subjetivos da comunicação com as dificuldades de compreensão do que é dito, aparece para Wolton (2004, p. 3031), como "uma das grandes revelações e contradições do século XX", e a técnica por não vislumbrar soluções, "devolve" o problema para teorias ancoradas na antropologia, ciência política, filosofia, história, sociologia e psicologia; as quais, conforme a Profa. Palmas III, são capazes de educar o olhar do jornalista.

Grosso modo, o que a professora de teórica L I, Dra. Lisboa I, da Universidade Católica Portuguesa percebe é, que o aluno chega na licenciatura com pré-noções sobre os estudos teóricos adquiridas no ensino secundário: "eu penso que vai para um lado já do que é o ensino secundário que também não é um ensino secundário orientado para o conhecimento ou para pensar. Os alunos quando chegam às universidades, também não têm essa experiência e, portanto, também resistem a isso, por outro lado, a relação que eles têm com os media, com a comunicação, com a tecnologia, enfim, ela envolve 


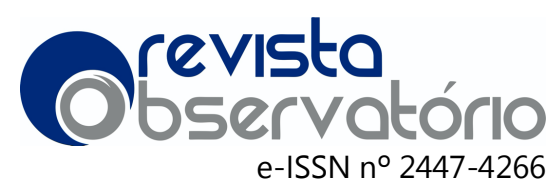

Vol. 6, n. 1, Janeiro-Março. 2020

todas as dimensões da vida e essa é uma relação muito prática [...]. Portanto, também têm uma resistência a pensar sobre a comunicação de outra forma, penso eu."

A constatação da professora Dra. Lisboa I, de os alunos resistirem a pensar a comunicação sob outros pontos de vista, mais uma vez apoia Wolton $(2004$, p. 37) quando diz que a comunicação do tipo facilitada pelas TICS, que "deveria aproximar os homens, serve para revelar tudo que os afasta", [...]. Parece haver um esforço político intencional de bloquear a criticidade juvenil, especialmente, quando se eliminam das matrizes curriculares do $2^{\circ}$ e $3^{\circ}$ graus, disciplinas como a sociologia. O professor catedrático de teórica M I, Dr. Minho da Universidade do Minho, "desconfia" que as ações das classes hegemônicas de despolitizar sistematicamente a população estudantil serve a propósitos de dominação: "Não é por acaso que o poder político atual está a tentar fazer desaparecer $x$ dos currículos escolares, não é por acaso, como também não é por acaso que em Portugal não existe $\mathrm{x}$ no secundário, também não é por acaso, porque preferem manter as pessoas, não digo ignorantes, mas despolitizadas e não conscientes nem conhecedoras da realidade, da situação da vida real, social; os nossos jovens, uma parte são despolitizados, por causa do tempo, eu sei que o espírito do tempo é difícil, mas sobretudo porque não têm acesso aos conhecimentos básicos, de cidadania, de conhecimento do que é a sociedade, do que é um partido, uma organização política, [...]."

Há sete anos, Machado (2011) falando sobre "o ensino de jornalismo na era da convergência" disse que o jornalismo vinha passando por profundas alterações desde os anos 80 como consequência das "reestruturações econômicas, políticas, sociais, culturais e educacionais vividas pelas sociedades contemporâneas", as quais provocaram quebras de paradigma no jornalismo (MACHADO, 2011, p. 7). Ocorre que, mudanças no modelo de ensino, modelos de simplificação intelectual, causam a estranheza apontada pelo professor Dr. Minho, se o objetivo do ensino cumprir sua missão, que é "produzir aprendizagem".

O grande medo é o de estar havendo o que o professor de teórica L II do Instituto de Ciências Sociais da Universidade de Lisboa, Dr. Lisboa II qualifica de "economia do conhecimento de nosso tempo, porque os conhecimentos estão a serviço da economia. Se é vendável ele é utilizado e valorizado... se a sociologia, filosofia tiverem algum produto para vender sim, se não, são consideradas não importantes, obsoletas. Obsoleto é o que não dá lucro." É a lógica do mercado.

\section{Conclusão}




\section{revisto \\ Observatório \\ e-ISSN n² 2447-4266}

Vol. 6, n. 1, Janeiro-Março. 2020

A serventia da sociologia da comunicação está presente nas comunicações diárias. Embora a maioria das análises que se faz das diversas mensagens veiculadas não sejam técnicas, ainda assim o receptor analisa a informação, a aceita ou descarta.

Relembrando que os argumentos introdutórios deste texto chamaram à atenção para o dano que a desinformação está causando a milhões de pessoas ao redor do mundo fica evidente que saber analisar a comunicação pode estar relacionado à salubridade ou morbidade considerando-se que grandes contingentes da população mundial agem displicentemente deixando-se levar por discursos outros que despriorizam a saúde.

A displicência também é glocalizada. Observam-se condutas displicentes em países desenvolvidos e periféricos, nos dois hemisférios, portanto há deficiência da e de sociologia da comunicação. Os grandes contingentes displicentes continuam precisando de analistas que lhes apresentem notícias sem filtros intencionais, papel que cabe ao jornalismo sério que atua incansavelmente na busca de informações verdadeiras mesmo sob o achincalhe de políticos e empresários, atuando como "guardião da sociedade."

Crises como esta que se estabeleceu demonstram a importância do ensino de sociologia nos cursos de jornalismo em função da necessidade de o futuro jornalista ter suficiente preparo para embasar a análise dos acontecimentos à luz da ciência. A plasticidade da sociologia (são mais de trinta aplicações) oferece ao jornalista subsídios teóricos que podem validar ou refutar informações a serem oferecidas ao público.

Professores de sociologia e de outras disciplinas do curso de jornalismo tanto no Brasil como em Portugal reconhecem que as universidades são pressionadas pelo mercado e alunos, pressão que as "obrigou" a enxugar currículos, excluindo disciplinas das ciências humanas como a sociologia. Felizmente, apesar destas circunstâncias, estes professores zelosos e outros inserem a teoria das ciências sociais e humanas nas ementas de seus cursos, como foi dito por uma professora, para "sensibilizar o olhar".

O panorama não é promissor porque a carência teórica dos estudantes dificulta a interdisciplinaridade em um curso caracteristicamente interdisciplinar. A base teórica oferece ao estudante a interlocução com teóricos das ciências sociais e outras ciências humanas, as quais facilitam interpretar a realidade. Disciplinas técnicas avançam com a evolução das TICs, "falam" a linguagem das máquinas, na sua maioria dispensam interpretações.

\section{Referências}

BBC. Available at <https://www.bbc.com/portuguese/internacional-52205918. 


\section{revisto \\ Observatório

Vol. 6, n. 1, Janeiro-Março. 2020

COVID PANDEMIA19. Available at <https://en.wikipedia.org/wiki/Pandemia_de_COVID19>. Accessed April 15, 2020.

DATA SHEET. Available at

< http://datafolha.folha.uol.com.br/opiniaopublica/2020/04/1988651-28-naoestao-em-isolamento-social-contr-coronavirus.shtml>. Accessed April 10, 2020.

FIDALGO, A. Teaching journalism in and for the 21st century. Communication given at the International Congress on Journalism and Internet, University of Coimbra, March 28 and 29, 2001. <Available at http: // www. bocc. ubi. pt [..., 2001 bocc.uff.br>. Access 19 out. 2016.

IBGE - Brazilian Institute of Geography and Statistics. Available at <https://www.ibge.gov.br/apps/populacao/projecao/index.html?utm_source=port al\&utm_medium=popclock\&utm_campaign=novo_popclock $>$. Accessed April 10, 2020.

JAMBEIRO, O.; PALÁCIOS, M. Brazilian perspectives in digital environments: communication policies, e-government, and digital journalism. Salvador, BA: EDUFBA, 2010.

LARANJEIRA, A.; QUADROS, C.; CAETANO, K. The teaching of digital journalism: methodologies that build a discipline. In: Teaching journalism in the era of convergence: concepts, methodology and case studies in Brazil. Elias Machado (Org.). Salvador: EDUFBA, 2011. P. 127-149.

LÉVI-STRAUSS, C. Cultural sociology, and its teaching. PLURAL, Journal of the Graduate Program in Sociology at USP, São Paulo, v.19.2, 2012, pp.129-137 Available at $<$ https://www.researchgate.net/publication/285546351_A_sociologia_cultural_e_se u_ensino>. Accessed 17 April 2020.

MACHADO, E. Preface. Teaching journalism in the era of convergence: concepts, methodology, and case studies in Brazil. Elias Machado (Org.). Salvador: EDUFBA, 2011. P. 7.

MELO, J. M. de. The nature of journalism and the mission of the journalist according to Costa Rego. Available at <http://www.portcom.intercom.org.br/pdfs/24c0adbd2ecb31b4737709c8dac8535 0.pdf>. Accessed April 15, 2020.

MELO, A. S. e. (2017). Enquadramento histórico legal do processo de bolonha e o seu impacto no sistema de ensino superior português. Revista Observatório, 3(6), 75141. https://doi.org/10.20873/uft.2447-4266.2017v3n6p75. 


\section{revisto \\ Observatório \\ e-ISSN n० 2447-4266}

Vol. 6, n. 1, Janeiro-Março. 2020

MOIO, I., Alcoforado, L., \& VIEIRA, C. C. (2017). A declaração de Bolonha e o reforço da abertura do ensino superior a novos públicos: perceções de pessoas adultas que frequentam a Universidade de Coimbra. Revista Observatório, 3(6), 169-201. https://doi.org/10.20873/uft.2447-4266.2017v3n6p169.

NUNES, S. G., PORTO JUNIOR, F. G. R., \& MORAES, N. R. de. (2017). Conhecimento e organização: indicativos pós-Bolonha de uma sociedade em construção. Revista Observatório, 3(6), 338-353. https://doi.org/10.20873/uft.24474266.2017v3n6p338.

PUBLIC. Available at <https://www.publico.pt/2020/04/14/economia/noticia/fmiconfinamento-sera-pior-recessao-desde-depressao-1912225>. Accessed April 15, 2020.

COVID PANDEMIA19. Available at < https://en.wikipedia.org/wiki/Pandemia_de_COVID19>. Accessed April 15, 2020.

RODRIGUES, J. M. Teaching and training in communication and journalism: a study on the sociology of communication discipline in journalism courses in Brazil and Portugal. Palmas, TO, 2018. Advisor: Prof. Dr. Francisco Gilson Rebouças Pôrto Júnior. Thesis (Master's degree).

THE LANCET. Covid19: learning from experience. Editorial. Volume 395, ISSUE 10229, P1011, March 28, 2020. Available at <https://www.thelancet.com/journals/lancet/article/PIIS0140-6736 (20) 30686-3 / full text>. Accessed April 16, 2020.

TEIXEIRA, P. O. The teaching of journalism in Portugal a history and analysis of curricular plans. Porto, 2009-2010. Supervisor: Prof. Dr. Jorge Pedro Sousa. Thesis (Master's degree). Fernando Pessoa University. 165 f. Available at <http://bdigital.ufp.pt/bitstream/10284/1681/2/DM_19061.pdf>. Access 04 set. 2017.

TEIXEIRA, P. O. Studies in Journalism and Media - Vol. 9 N 2 - July to December 2012. Access 09 Sep. 2016.

TEIXEIRA, T. Pedagogical projects in times of change in journalism. In: Teaching journalism in the era of convergence: concepts, methodology, and case studies in Brazil. Elias Machado (Org.). Salvador: EDUFBA, 2011. P. 17-31.

THOMPSON, J. B. Ideology, and modern culture: critical social theory in the era of mass media. 9. ed. Petrópolis, RJ: Vozes, 2011.

WARDLE, C.; DERAKHSHAN, H. Information Disorder. Toward an interdisciplinary framework for research and policymaking. Available at 


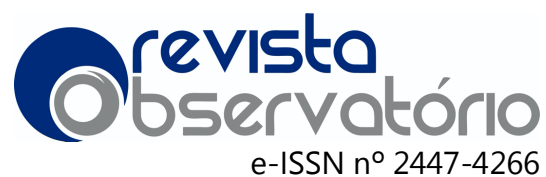

Vol. 6, n. 1, Janeiro-Março. 2020

<https://rm.coe.int/information-disorder-report-november-2017/1680764666>.

Accessed April 15, 2020.

WESTCOTT, B. China issues a previous list of animals that can be raised for meat

consumption. Available at

< https://www.cnnbrasil.com.br/internacional/2020/04/10/china-emite-lista-

previa-de-animais-que-podem-ser-criados-para-consumo-da-carne $>$. Accessed

17 April 2020.

WOLTON, D; MOURA, D.; ADGHIRNI, Z. L. Thinking about communication. Brasília, DF: Ed.

UnB. 2004.

\begin{abstract}
:
We are experiencing an avalanche of false news about the reality of the facts. Real news can be the difference between living or dying for millions of people across the globe although access to real news may be the privilege of a few. This text will present aspects of the sociology of communication, its relevance in journalistic training and the resilience of the journalist - why teaching sociology in the journalism course. It is observed that the carelessness is glocalized. Careless behavior is observed in developed and peripheral countries, in both hemispheres, so there is a deficiency in the sociology of communication. The large nonchalant contingents continue to need analysts to present news to them without intentional filters, a role that lies with serious journalism that works tirelessly in search of true information even under the clash of politicians and businessmen, acting as "guardian of society."
\end{abstract}

KEYWORDS: Sociology of Journalism; formation; Communication; fake news.

\section{RESUMEN:}

Estamos experimentando una avalancha de noticias falsas sobre la realidad de los hechos. Las noticias reales pueden ser la diferencia entre vivir o morir para millones de personas en todo el mundo, aunque el acceso a noticias reales puede ser el privilegio de unos pocos. Este texto presentará aspectos de la sociología de la comunicación, su relevancia en la formación periodística y la resistencia del periodista: por qué enseñar sociología en el curso de periodismo. Se observa que el descuido está glocalizado. Hay comportamientos negligentes en los países desarrollados y periféricos, en ambos hemisferios, por lo que hay una deficiencia en la comunicación y la sociología. Los grandes contingentes indiferentes continúan necesitando analistas para presentarles noticias sin filtros intencionales, un papel que recae en el periodismo serio que trabaja incansablemente en busca de información verdadera incluso bajo el choque de políticos y empresarios, actuando como "guardianes de la sociedad".

PALABRAS CLAVE: Sociología del periodismo; formación; Comunicación; noticias falsas. 